Article

\title{
Drug-Induced Gingival Overgrowth: The Effect of Cyclosporin A and Mycophenolate Mophetil on Human Gingival Fibroblasts
}

\author{
Dorina Lauritano ${ }^{1, *,+(\mathbb{D})}$, Giulia Moreo ${ }^{1, \dagger}{ }^{,}$Luisa Limongelli ${ }^{2}\left(\mathbb{D}\right.$, Annalisa Palmieri ${ }^{3}(\mathbb{C}$ \\ and Francesco Carinci ${ }^{4}$ \\ 1 Department of Medicine and Surgery, Centre of Neuroscience of Milan, University of Milano-Bicocca, \\ 20126 Milan, Italy; moreo.giulia@gmail.com \\ 2 Interdisciplinary Department of Medicine, University of Bari, 70121 Bari, Italy; \\ luisanna.limongelli@gmail.com \\ 3 Department of Experimental, Diagnostic and Specialty Medicine, University of Bologna, via Belmoro 8, \\ 40126 Bologna, Italy; plmnls@unife.it \\ 4 Department of Morphology, Surgery and Experimental Medicine, University of Ferrara, 44121 Ferrara, Italy; \\ crc@unife.it \\ * Correspondence: dorina.lauritano@unimib.it; Tel.: +39-33-5679-0163 \\ + These authors contributed equally to this work.
}

Received: 19 June 2020; Accepted: 15 July 2020; Published: 17 July 2020

check for updates

\begin{abstract}
Drug-induced gingival overgrowth may occur after a chronic administration of three classes of systemic drugs: Anticonvulsants, immunosuppressants, and calcium channel blockers. This study aimed to investigate how cyclosporin A and mycophenolate mophetil (immunosuppressive drugs) could interfere with human gingival fibroblasts functions, leading to gingival enlargement. Human gingival fibroblasts derived from the tissue of a 60-year-old female were cultured in a DMEME medium. A stock solution with $1 \mathrm{mg} / \mathrm{mL}$ of mycophenolate and $1 \mathrm{mg} / \mathrm{mL}$ of cyclosporine were prepared and dissolved in a DMEM medium to prepare a serial dilution at the concentrations of 5000, 2000, 1000, 500, and $100 \mathrm{ng} / \mathrm{mL}$, for both treatments. Cell viability was measured using the PrestoBlue ${ }^{\mathrm{TM}}$ Reagent Protocol. Quantitative real-time RT-PCR was performed in order to analyze the expression of 57 genes coding for gingival fibroblasts "Extracellular Matrix and Adhesion Molecules". Mycophenolate and cyclosporine had no effect on fibroblast cell viability at $1000 \mathrm{ng} / \mathrm{mL}$. Both the treatments showed similar effects on the expression profiling of treated cells: Downregulation of most extracellular matrix metalloproteases genes (MMP8, MMP11, MMP15, MMP16, MMP24) was assessed, while CDH1, ITGA2, ITGA7, LAMB3, MMP12, and MMP13 were recorded to be upregulated in fibroblasts treated with immunosuppressive drugs. It has been demonstrated that gingival overgrowth can be caused by the chronic administration of cyclosporin $\mathrm{A}$ and mycophenolate mophetil. However, given the contrasting data of literature, further investigations are needed, making clear the possible effects of immunosuppressive drugs on fibroblasts.
\end{abstract}

Keywords: mycophenolate mophetil; cyclosporin A; gingival hyperplasia; gingival overgrowth; periodontal disease

\section{Introduction}

Gingival fibromatosis (also called gingival overgrowth or hyperplasia) can be defined as a pathological diffused or local growth of marginal and attached gingiva or interdental papilla [1]. Gingival overgrowth (GO) may cause severe consequences for the dento-maxillary apparatus: Inflammatory reaction may aggravate the periodontal condition, leading to tooth loss, while speech 
capacity, chewing, and aesthetic may be altered [2,3]. The ethiopathogenetic mechanisms may derive from idiopathic, hereditary, or drug-induced forms [1]. Drug-induced GO is a side-effect, which may occur after the administration of certain systemic drugs, whose target organ is not the gingival tissue [4]. According to the literature, GO may be related to more than 20 drugs [5-7] and, in particular, it could manifest itself as a result of chronic usage of three main classes of drugs: Anticonvulsants, immunosuppressants, and calcium channel blockers [8]. A study by Hatahira et al. (2017) [9] reported that more than 70\% of GO incidence was associated with cyclosporine (immunosuppressant) administration, while nifedipine (calcium channel blocker) and phenytoin (anticonvulsant) administration cause GO in 6-15\% and 50\% of individuals, respectively. The American Academy of Periodontology (2004) recorded a prevalence rate related to nifedipine, cyclosporine, and phenytoin of $6-15 \%, 25-30 \%$, and $50 \%$, respectively. A connective tissue response, characterized by an excessive accumulation of extracellular matrix proteins or amorphous ground substance, seems to be responsible for the increase of gingival tissue volume [10,11]. Possible risk factors for a drug-induced GO onset are: Poor plaque control, male gender (with a risk three times higher than the female), age (with inverse correlation), and genetic predisposition [10,12]. Cyclosporine A (CsA) provides an immunosuppressive effect and it is widely administrated in case of organ transplantation, in order to prevent acute or chronic rejection and in patients with autoimmune diseases. Mycophenolate (Mf) is used in many different immunosuppressive protocols, since it was demonstrated that it has a manageable toxicity: The study by van Gelder et al. showed that Mf, added to CsA in an immunosuppressive protocol, reduced the incidence of acute rejection after renal transplantation from $40-45 \%$ to $20-25 \%$ compared to placebo or azathioprine-based therapies $[13,14]$. The action of both drugs is directed to the T-cell activation cascade. The inhibition of transcription performed by CsA is made possible thanks to the formation of a heterodimeric complex (consisting of the drug and its cytoplasmic receptor protein: Cyclophilin), which binds calcineurin and inhibits its phosphatase activity; in this way the expression of nuclear regulatory proteins and T-cell activation genes are inhibited. Mf develops its function of nucleotide synthesis inhibitor, stopping the action of inosine monophosphate dehydrogenase and thus preventing the biosynthesis of guanosine and deoxyguanosine; this cascade of event leads to a selective inhibition of T- and B-cell proliferation [15]. Although the association between CsA and gingival hyperplasia has been widely demonstrated $[4,16]$, the role of $\mathrm{Mf}$ in GO remains unclear, since the number of the researches in this regard is limited: Trandafir et al. [17] reported the case of a 29 year-old male patient, receiving immunosuppressive therapy with CsA and Mf, who developed gingival enlargement; furthermore, a study in 2010 compared two immunosuppressive protocols, which included cyclosporine and prednisolone with Mf or azathioprine, respectively, reporting no difference in terms of gingival overgrowth [18]. However, the study by de la Rosa García [19] supported the theory according to which Mf may present a protective effect against GO.

\subsection{Role of Cyclosporine A and Mycophenolate Mophetil on Gingival Hyperplasia}

GO becomes clinically observable 1 or 3 months after the start of the immunosuppressive therapy and reaches a plateau phase at 9 to 12 months: It manifests initially on the interdental papillae as a localized nodular enlargement, later extending to the dental crown (from an horizontal to a vertical growth) and it is more frequent in the vestibular side of the maxillary and mandibular frontal regions $[12,20,21]$. It has been demonstrated that, unlike the anticonvulsants and calcium channel blockers-induced gingival hyperplasia, GO associated with the immunosuppressive therapy is characterized by a high inflammation level with a low fibrosis: In particular, CsA leads to an exaggerated innate immune response, targeting cyclophilin and inhibiting T-cell production of interleukin-2 and it provides an anti-fibrotic effect on collagen biosynthesis and deposition [22]. From the histological point of view, the enlargement of the gingiva caused by CsA and Mf could be defined as a connective tissue disorder, marked by incremented interstitial collagen deposition and extracellular matrix proteins production, plasma cell infiltration, increased inflammatory response (increased number 
of inflammatory cells, such as macrophages), and altered vascularisation $[17,23,24]$. As reported in the literature, immunosuppressive drugs may interfere with the gingival fibroblasts (GFs) function, altering the transcription of several cytokines, such as transforming growth factor- $\beta 1$ (TGF- $\beta 1$ ), interleukin-6 and $-8(I L-6, I L-8)$, interleukin-1 $\beta(I L-1 \beta)$, and fibroblast growth factor $(F G F)[5,25,26]$. The proliferation of human gingival fibroblasts (HGF) could be stimulated by the long term administration of immunosuppressive drugs [16,27-29]; however, some researches highlighted that the effect of CsA on gingival fibroblasts depends on its dose: A long-term exposure to a low dose of the drug $(\leq 200 \mathrm{ng} / \mathrm{mL})$ does not have any influence on the viability and proliferation of these cells, parameters which are inhibited by higher doses of CsA $(400-800 \mathrm{ng} / \mathrm{mL})[30,31]$. IL-6 is recorded to be highly expressed by the gingival connective tissue fibroblasts in the case of immunosuppressive therapy induced GO, increasing the synthesis of collagen and glycosaminoglycan [10]. Gong et al. [32] recorded higher gingival crevicular fluid IL-1 $\beta$ levels in CsA induced GO, which is responsible for the upregulation of the IL-6 secretion in gingival fibroblasts. Wu et al. [33] found out that the higher expression of TGF- $\beta 1$, which has the capacity to enhance collagen production and to decrease collagen degradation, may promote the profibrotic activity of CsA. The same study demonstrated that CsA also increases the synthesis of the connective tissue growth factor $\left(C T G F / C C N_{2}\right)$, which induces the profibrotic effect of TGF- $\beta 1$.

\subsection{Objective}

An increase in gingival tissue following the administration of anticonvulsants, immunosuppressants, and calcium channel blockers drugs are characterized by fibroblasts hyperproliferation of the connective tissue with a deposition of the extracellular matrix. In addition, cell proliferation involves epithelial-mesenchymal transition resulting in changes in the expression of adhesion molecules.

In this study, the authors investigated how cyclosporin A and michophenolate mophetil could affect human gingival fibroblasts, leading to the onset of gingival overgrowth. In particular, the cell viability and the expression of 57 genes coding for gingival fibroblasts "Extracellular Matrix and Adhesion Molecules" were assessed.

\section{Experimental Section}

\subsection{Primary Human Fibroblast Cells Culture}

Fibroblasts at the second replication step, originating from the gingiva of a 60-year-old woman, were purchased from ATCC ${ }^{\circledR}$ Cell Lines. The fibroblasts were maintained in a humidified atmosphere of $5 \% \mathrm{CO}_{2}$, at $37{ }^{\circ} \mathrm{C}$ and replicated in a DMEM medium added with $10 \%$ fetal calf serum (FBS), antibiotics, and amino acids (Sigma-Aldrich, Inc., St Louis, MO, USA).

\subsection{Cell Viability Test}

Human gingival fibroblasts were seeded into 96-well plates at a density of $10^{4}$ cells per well containing $100 \mu \mathrm{L}$ of a cell culture medium and incubated for $24 \mathrm{~h}$ to allow cell adherence.

A stock solution with $1 \mathrm{mg} / \mathrm{mL}$ of mycophenolate and $1 \mathrm{mg} / \mathrm{mL}$ of cyclosporine were prepared and dissolved in a DMEM medium to prepare the serial dilution at concentrations of 5000, 2000, 1000, 500 , and $100 \mathrm{ng} / \mathrm{mL}$, for both treatments.

A set of wells were treated with mycophenolate, three wells for each concentration. Another set of wells were treated with cyclosporine. The cell culture medium alone was used as a negative control.

After $24 \mathrm{~h}$ of incubation, cell viability was measured using the PrestoBlue ${ }^{\mathrm{TM}}$ Reagent Protocol (Invitrogen, Carlsbad, CA, USA) according to the manufacturer's instructions, as previously described [5].

\subsection{Cell Treatment and RNA Isolation}

Fibroblasts seeded at the density of $1.0 \times 10^{5}$ cells/mL were cultivated for $16 \mathrm{~h}$ with a serum-free medium in order to normalize the gene expression of the cells. 
Subsequently, the cells were treated with cyclosporine and mycophenolate. Each solution was prepared dissolving $1000 \mathrm{ng} / \mathrm{mL}$ of the treatment in a DMEM medium containing $2 \%$ of FBS, antibiotics, and amino acids. At the end of the treatment, which lasted $24 \mathrm{~h}$, the cells were detached by trypsin and the RNA was isolated using the GenElute mammalian total RNA purification miniprep kit (Sigma-Aldrich), according to the manufacturer's instructions.

\subsection{Reverse Transcription and Quantitative Real-Time RT-PCR}

The fibroblast cDNA was synthesized starting from 500 ng of total RNA using the PrimeScript RT Master Mix kit (Takara Bio Inc., Kusatsu, Shiga Prefecture, Japan) and subsequently used to amplify the genes belonging to the "Extracellular Matrix and Adhesion Molecules" pathway using a custom primer (Sigma-Aldrich, Inc., St Louis, MO, USA).

The genes were selected on the basis of superarray platforms (SAB Biosciences, Frederick, MD, USA) that analyze specific pathways of interest.

The amplification was conducted on a quantitative real-time PCR using the ViiA ${ }^{\mathrm{TM}} 7$ System (Applied Biosystems, Foster City, CA, USA). The CDNA synthesis and amplification protocol were previously described by Lauritano et al. 2019 [34].

\subsection{Statistical Analysis}

The gene expression analysis was carried out using the delta/delta Ct method [35] using RPL13 as a reference gene. Each fold change was obtained by comparing the gene expression of the treated cells compared to the control ones.

\section{Results}

The cell viability test conducted on cells served to establish the most suitable concentration for an in vitro treatment such as to determine changes in gene expression without however killing the cells. The PrestoBlue ${ }^{\mathrm{TM}}$ assay determined that this concentration for both the treatments was $1000 \mathrm{ng} / \mathrm{mL}$.

In order to evaluate the effects induced by cyclosporine and mycophenolate, 57 genes belonging to the "Extracellular Matrix and Adhesion Molecules" pathway were amplified in fibroblasts after $24 \mathrm{~h}$ of treatment. Tables 1 and 2 show the gene expression values as a Fold Change following the treatment with mycophenolate and cyclosporine, respectively. The bold values represent the statistically significant results (fold change $\geq 2$ and $p$-value $\leq 0.05$ for upregulated genes, and fold change $\leq 0.5$ and $p$-value $\leq 0.05$ for significantly downregulated genes) that were collected in Tables 3 and 4 . Following the treatment for $24 \mathrm{~h}$, both substances induced overexpression of the same genes in fibroblasts, including the adhesion molecules $C D H 1$ and genes involved in the deposition of the extracellular matrix such as ITGA2, ITGA7, LAMB3, MMP12, and MMP13. Among the genes significantly downregulated by both treatments there are the extracellular matrix metalloproteases MMP8, MMP11, MMP15, MMP16, MMP24. Figure 1A,B represents significantly expression levels of the genes up- and downregulated in fibroblast cells treated with mycophenolate and cyclosporine, respectively. In order to confirm the expression results obtained by the real-time PCR, it was decided to measure the protein levels of CDH1 by the enzyme immunoassay test (ELISA). The ELISA test confirmed the real-time PCR results showing an increase in CDH1 equal to 5.13-fold \pm 0.16 for the mycophenolate treatment and 5.05-fold \pm 0.20 for the cyclosporine treatment.

Authors decided to evaluate the $C D H 1$ expression because it is one of the genes that showed the greatest fold change. Furthermore, adhesion proteins such as CDH1 being expressed on the cell surface are easily quantifiable with immunoenzymatic methods such as ELISA. 
Table 1. Gene expression profile of 57 genes belonging to the "Extracellular Matrix and Adhesion Molecules" pathway analyzed using real-time PCR after $24 \mathrm{~h}$ of treatment with mycophenolate.

\begin{tabular}{|c|c|c|}
\hline Gene & Fold Change & Gene Function \\
\hline CD44 & 1.56 & Cell-Cell Adhesion (MIM:107269) \\
\hline CDH1 & 4.62 & Cell-Cell Adhesion (MIM:192090) \\
\hline COL1A2 & 2.20 & Collagens and Extracellular Matrix Structural constituent (MIM:192090) \\
\hline COL2A1 & 1.71 & Collagens and Extracellular Matrix Structural constituent (MIM:120140) \\
\hline COL3A1 & 1.71 & Collagens and Extracellular Matrix Structural constituent (MIM:120180) \\
\hline COL4A1 & 3.43 & Collagens and Extracellular Matrix Structural constituent (MIM:120130) \\
\hline COL5A1 & 1.31 & Collagens and Extracellular Matrix Structural constituent (MIM:120215) \\
\hline COL6A1 & 1.69 & Collagens and Extracellular Matrix Structural constituent (MIM:120220) \\
\hline COL7A1 & 0.74 & Collagens and Extracellular Matrix Structural constituent (MIM:120120) \\
\hline COL8A1 & 2.54 & Collagens and Extracellular Matrix Structural constituent (MIM:120251) \\
\hline COL9A1 & 1.42 & Collagens and Extracellular Matrix Structural constituent (MIM:120210) \\
\hline COL10A1 & 2.10 & Collagens and Extracellular Matrix Structural constituent (MIM:120110) \\
\hline COL11A1 & 1.95 & Collagens and Extracellular Matrix Structural constituent (MIM:120280) \\
\hline CTNNA1 & 2.19 & Cell Adhesion Molecule (MIM:116805) \\
\hline CTNNB1 & 2.36 & Cell Adhesion Molecule (MIM:116806) \\
\hline CTNND2 & 0.95 & Cell Adhesion Molecule (MIM:604275) \\
\hline FN1 & 1.03 & Cell Adhesion Molecule (MIM:135600) \\
\hline HAS1 & 1.86 & Transmembrane Receptor (MIM:601463) \\
\hline ILF3 & 1.73 & Transmembrane Receptor (MIM:603182) \\
\hline ITGA1 & 3.72 & Transmembrane Receptor (MIM:192968) \\
\hline ITGA2 & 5.30 & Transmembrane Receptor (MIM:192974) \\
\hline ITGA3 & 3.04 & Transmembrane Receptor (MIM:605025) \\
\hline ITGA4 & 1.71 & Transmembrane Receptor (MIM:192975) \\
\hline ITGA5 & 2.82 & Transmembrane Receptor (MIM:135620) \\
\hline ITGA6 & 1.84 & Transmembrane Receptor (MIM:147556) \\
\hline ITGA7 & 4.81 & Transmembrane Receptor (MIM:600536) \\
\hline ITGA8 & 1.82 & Transmembrane Receptor (MIM:604063) \\
\hline ITGB1 & 2.22 & Transmembrane Receptor (MIM:135630) \\
\hline ITGB2 & 0.91 & Transmembrane Receptor (MIM:600065) \\
\hline ITGB4 & 0.59 & Transmembrane Receptor (MIM:147557) \\
\hline ITGB5 & 1.46 & Transmembrane Receptor (MIM:147561) \\
\hline LAMA1 & 1.30 & Basement Membrane Constituent (MIM:150320) \\
\hline$L A M A 2$ & 0.12 & Basement Membrane Constituent (MIM:156225) \\
\hline$L A M A 3$ & 1.63 & Basement Membrane Constituent (MIM:600805) \\
\hline$L A M B 1$ & 0.50 & Basement Membrane Constituent (MIM:150240) \\
\hline$L A M B 2$ & 2.08 & Basement Membrane Constituent (MIM:150325) \\
\hline$L A M B 3$ & 4.86 & Basement Membrane Constituent (MIM:150310) \\
\hline MMP2 & 1.61 & Extracellular Matrix Protease (MIM:120360) \\
\hline MMP3 & 2.90 & Extracellular Matrix Protease (MIM:185250) \\
\hline MMP7 & 2.37 & Extracellular Matrix Protease (MIM:178990) \\
\hline MMP8 & 0.45 & Extracellular Matrix Protease (MIM:120355) \\
\hline MMP9 & 1.43 & Extracellular Matrix Protease (MIM:120361) \\
\hline MMP10 & 4.59 & Extracellular Matrix Protease (MIM:185260) \\
\hline MMP11 & 0.03 & Extracellular Matrix Protease (MIM:185261) \\
\hline MMP12 & 4.26 & Extracellular Matrix Protease (MIM:601046) \\
\hline MMP13 & 3.82 & Extracellular Matrix Protease (MIM:600108) \\
\hline MMP14 & 1.20 & Extracellular Matrix Protease (MIM:600754) \\
\hline MMP15 & 0.06 & Extracellular Matrix Protease (MIM:602261) \\
\hline MMP16 & 0.42 & Extracellular Matrix Protease (MIM:602262) \\
\hline$M M P 24$ & 0.09 & Extracellular Matrix Protease (MIM:604871) \\
\hline$M M P 26$ & 3.43 & Extracellular Matrix Protease (MIM:605470) \\
\hline TGFB1 & 1.51 & TGF- $\beta$ Signaling (MIM:190180) \\
\hline TGFB2 & 1.25 & TGF- $\beta$ Signaling (MIM:190220) \\
\hline TGFB3 & 1.05 & TGF- $\beta$ Signaling (MIM:190230) \\
\hline TIMP1 & 1.09 & Extracellular Matrix Protease Inhibitor (MIM:305370) \\
\hline$V C A N$ & 1.07 & Cell Adhesion Molecule (MIM:118661) \\
\hline RPL13 & 1.00 & Housekeeping gene (MIM:113703) \\
\hline
\end{tabular}

The bold values represent the statistically significant results (fold change $\geq 2$ and $p$-value $\leq 0.05$ for upregulated genes, and fold change $\leq 0.5$ and $p$-value $\leq 0.05$ for significantly downregulated genes). 
Table 2. Gene expression profile of 57 genes belonging to the "Extracellular Matrix and Adhesion Molecules" pathway analyzed using real-time PCR after $24 \mathrm{~h}$ of treatment with cyclosporine [34].

\begin{tabular}{|c|c|c|}
\hline Gene & Fold Change & Gene Function \\
\hline CD44 & 0.74 & Cell-Cell Adhesion (MIM:107269) \\
\hline CDH1 & 5.01 & Cell-Cell Adhesion (MIM:192090) \\
\hline COL1A2 & 0.92 & Collagens and Extracellular Matrix Structural constituent (MIM:192090) \\
\hline COL2A1 & 0.62 & Collagens and Extracellular Matrix Structural constituent (MIM:120140) \\
\hline COL3A1 & 0.85 & Collagens and Extracellular Matrix Structural constituent (MIM:120180) \\
\hline COL4A1 & 1.73 & Collagens and Extracellular Matrix Structural constituent (MIM:120130) \\
\hline COL5A1 & 0.62 & Collagens and Extracellular Matrix Structural constituent (MIM:120215) \\
\hline COL6A1 & 0.82 & Collagens and Extracellular Matrix Structural constituent (MIM:120220) \\
\hline COL7A1 & 0.26 & Collagens and Extracellular Matrix Structural constituent (MIM:120120) \\
\hline COL8A1 & 0.85 & Collagens and Extracellular Matrix Structural constituent (MIM:120251) \\
\hline COL9A1 & 0.91 & Collagens and Extracellular Matrix Structural constituent (MIM:120210) \\
\hline COL10A1 & 0.97 & Collagens and Extracellular Matrix Structural constituent (MIM:120110) \\
\hline COL11A1 & 0.85 & Collagens and Extracellular Matrix Structural constituent (MIM:120280) \\
\hline CCTNA1 & 1.25 & Cell Adhesion Molecule (MIM:116805) \\
\hline CTNB & 1.27 & Cell Adhesion Molecule (MIM:116806) \\
\hline CTNND2 & 0.96 & Cell Adhesion Molecule (MIM:604275) \\
\hline FN1 & 0.56 & Cell Adhesion Molecule (MIM:135600) \\
\hline HAS1 & 0.97 & Transmembrane Receptor (MIM:601463) \\
\hline$I L F 3$ & 0.93 & Transmembrane Receptor (MIM:603182) \\
\hline ITGA1 & 1.31 & Transmembrane Receptor (MIM:192968) \\
\hline ITGA2 & 2.05 & Transmembrane Receptor (MIM:192974) \\
\hline ITGA3 & 1.47 & Transmembrane Receptor (MIM:605025) \\
\hline ITGA4 & 0.99 & Transmembrane Receptor (MIM:192975) \\
\hline ITGA5 & 1.51 & Transmembrane Receptor (MIM:135620) \\
\hline ITGA6 & 1.08 & Transmembrane Receptor (MIM:147556) \\
\hline ITGA7 & 2.75 & Transmembrane Receptor (MIM:600536) \\
\hline ITGA8 & 0.77 & Transmembrane Receptor (MIM:604063) \\
\hline ITGB1 & 1.03 & Transmembrane Receptor (MIM:135630) \\
\hline ITGB2 & 0.34 & Transmembrane Receptor (MIM:600065) \\
\hline ITGB4 & 0.19 & Transmembrane Receptor (MIM:147557) \\
\hline ITGB5 & 0.63 & Transmembrane Receptor (MIM:147561) \\
\hline LAMA1 & 0.71 & Basement Membrane Constituent (MIM:150320) \\
\hline$L A M A 2$ & 0.15 & Basement Membrane Constituent (MIM:156225) \\
\hline$L A M A 3$ & 0.89 & Basement Membrane Constituent (MIM:600805) \\
\hline$L A M B 1$ & 0.06 & Basement Membrane Constituent (MIM:150240) \\
\hline$L A M B 2$ & 1.08 & Basement Membrane Constituent (MIM:150325) \\
\hline$L A M B 3$ & 2.37 & Basement Membrane Constituent (MIM:150310) \\
\hline MMP2 & 0.77 & Extracellular Matrix Protease (MIM:120360) \\
\hline MMP3 & 1.05 & Extracellular Matrix Protease (MIM:185250) \\
\hline MMP7 & 0.78 & Extracellular Matrix Protease (MIM:178990) \\
\hline MMP8 & 0.05 & Extracellular Matrix Protease (MIM:120355) \\
\hline MMP9 & 0.92 & Extracellular Matrix Protease (MIM:120361) \\
\hline MMP10 & 1.70 & Extracellular Matrix Protease (MIM:185260) \\
\hline MMP11 & 0.03 & Extracellular Matrix Protease (MIM:185261) \\
\hline MMP12 & 2.07 & Extracellular Matrix Protease (MIM:601046) \\
\hline MMP13 & 2.03 & Extracellular Matrix Protease (MIM:600108) \\
\hline MMP14 & 0.98 & Extracellular Matrix Protease (MIM:600754) \\
\hline MMP15 & 0.05 & Extracellular Matrix Protease (MIM:602261) \\
\hline MMP16 & 0.31 & Extracellular Matrix Protease (MIM:602262) \\
\hline$M M P 24$ & 0.04 & Extracellular Matrix Protease (MIM:604871) \\
\hline$M M P 26$ & 0.49 & Extracellular Matrix Protease (MIM:605470) \\
\hline TGFB1 & 1.24 & TGF- $\beta$ Signaling (MIM:190180) \\
\hline TGFB2 & 0.74 & TGF- $\beta$ Signaling (MIM:190220) \\
\hline TGFB3 & 0.77 & TGF- $\beta$ Signaling (MIM:190230) \\
\hline TIMP1 & 0.88 & Extracellular Matrix Protease Inhibitor (MIM:305370) \\
\hline$V C A N$ & 0.88 & Cell Adhesion Molecule (MIM:118661) \\
\hline RPL13 & 1.00 & Housekeeping gene (MIM:113703) \\
\hline
\end{tabular}

The bold values represent the statistically significant results (fold change $\geq 2$ and $p$-value $\leq 0.05$ for upregulated genes, and fold change $\leq 0.5$ and $p$-value $\leq 0.05$ for significantly downregulated genes). 
Table 3. Significant gene expression levels after $24 \mathrm{~h}$ of treatment with mycophenolate, as compared with untreated cells.

\begin{tabular}{|c|c|c|c|}
\hline Gene & Fold Change & $\operatorname{SD}(+/-)$ & Gene Function \\
\hline CDH1 & 4.62 & 0.00 & Cell-Cell Adhesion \\
\hline COL1A2 & 2.20 & 0.07 & Collagens and Extracellular Matrix Structural constituent \\
\hline COL4A1 & 3.43 & 0.15 & Collagens and Extracellular Matrix Structural constituent \\
\hline COL8A1 & 2.54 & 0.02 & Collagens and Extracellular Matrix Structural constituent \\
\hline COL10A1 & 2.10 & 0.00 & Collagens and Extracellular Matrix Structural constituent \\
\hline CCTNA1 & 2.19 & 0.07 & Cell Adhesion Molecule \\
\hline CTNB & 2.36 & 0.06 & Cell Adhesion Molecule \\
\hline ITGA1 & 3.72 & 0.18 & Transmembrane Receptor \\
\hline ITGA2 & 5.30 & 0.16 & Transmembrane Receptor \\
\hline ITGA3 & 3.04 & 0.12 & Transmembrane Receptor \\
\hline ITGA5 & 2.82 & 0.15 & Transmembrane Receptor \\
\hline ITGA7 & 4.81 & 0.06 & Transmembrane Receptor \\
\hline ITGB1 & 2.22 & 0.29 & Transmembrane Receptor \\
\hline$L A M B 2$ & 2.08 & 0.00 & Basement Membrane Constituent \\
\hline$L A M B 3$ & 4.86 & 0.10 & Basement Membrane Constituent \\
\hline MMP3 & 2.90 & 0.02 & Extracellular Matrix Protease \\
\hline$M M P 7$ & 2.37 & 0.48 & Extracellular Matrix Protease \\
\hline MMP8 & 0.45 & 0.00 & Extracellular Matrix Protease \\
\hline MMP10 & 4.59 & 0.17 & Extracellular Matrix Protease \\
\hline MMP11 & 0.03 & 0.00 & Extracellular Matrix Protease \\
\hline MMP12 & 4.26 & 0.02 & Extracellular Matrix Protease \\
\hline MMP13 & 3.82 & 0.26 & Extracellular Matrix Protease \\
\hline MMP15 & 0.06 & 0.00 & Extracellular Matrix Protease \\
\hline MMP16 & 0.42 & 0.02 & Extracellular Matrix Protease \\
\hline MMP24 & 0.09 & 0.02 & Extracellular Matrix Protease \\
\hline MMP26 & 3.43 & 0.39 & Extracellular Matrix Protease \\
\hline
\end{tabular}

Fold change $\geq 2$ and $p$-value $\leq 0.05$ for upregulated genes, and fold change $\leq 0.5$ and $p$-value $\leq 0.05$ for significantly downregulated genes.

Table 4. Significant gene expression levels after $24 \mathrm{~h}$ of treatment with cyclosporine, as compared with untreated cells [34].

\begin{tabular}{cccc}
\hline Gene & Fold Change & SD $(+/-)$ & Gene Function \\
\hline CDH1 & 5.01 & 0.17 & Cell-Cell Adhesion \\
COL7A1 & 0.26 & 0.02 & Collagens and Extracellular Matrix Structural constituent \\
ITGA2 & 2.05 & 0.07 & Transmembrane Receptor \\
ITGA7 & 2.75 & 0.52 & Transmembrane Receptor \\
ITGB2 & 0.34 & 0.12 & Transmembrane Receptor \\
ITGB4 & 0.19 & 0.02 & Transmembrane Receptor \\
LAMA2 & 0.15 & 0.02 & Basement Membrane Constituent \\
LAMB1 & 0.06 & 0.00 & Basement Membrane Constituent \\
LAMB3 & 2.37 & 0.14 & Basement Membrane Constituent \\
$M M P 8$ & 0.05 & 0.01 & Extracellular Matrix Protease \\
$M M P 11$ & 0.03 & 0.00 & Extracellular Matrix Protease \\
$M M P 12$ & 2.07 & 0.08 & Extracellular Matrix Protease \\
$M M P 13$ & 2.03 & 0.01 & Extracellular Matrix Protease \\
$M M P 15$ & 0.05 & 0.01 & Extracellular Matrix Protease \\
$M M P 16$ & 0.31 & 0.02 & Extracellular Matrix Protease \\
$M M P 24$ & 0.04 & 0.01 & Extracellular Matrix Protease \\
$M M P 26$ & 0.49 & 0.15 & Extracellular Matrix Protease \\
\hline
\end{tabular}

Fold change $\geq 2$ and $p$-value $\leq 0.05$ for upregulated genes, and fold change $\leq 0.5$ and $p$-value $\leq 0.05$ for significantly downregulated genes. 
A

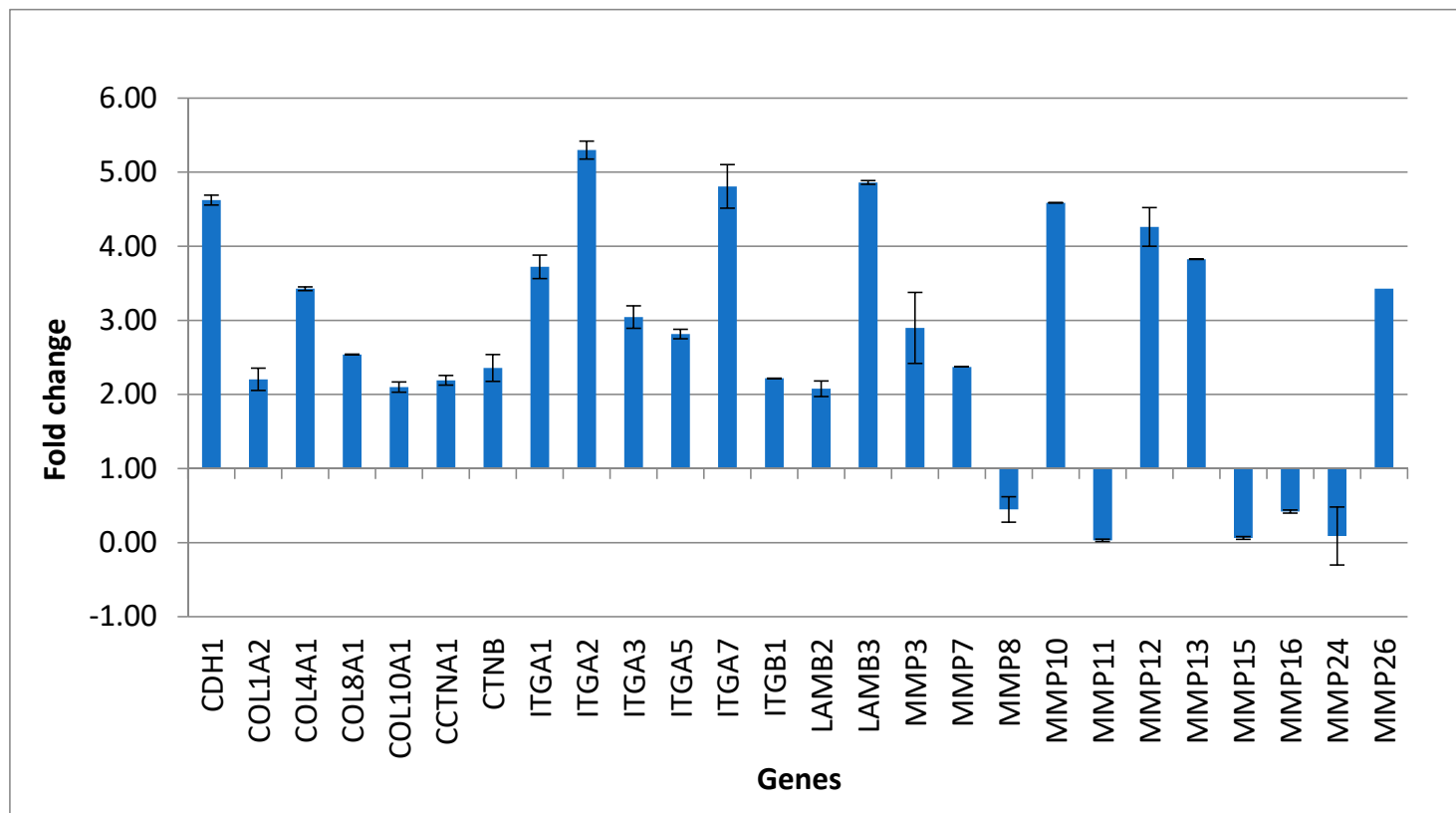

B

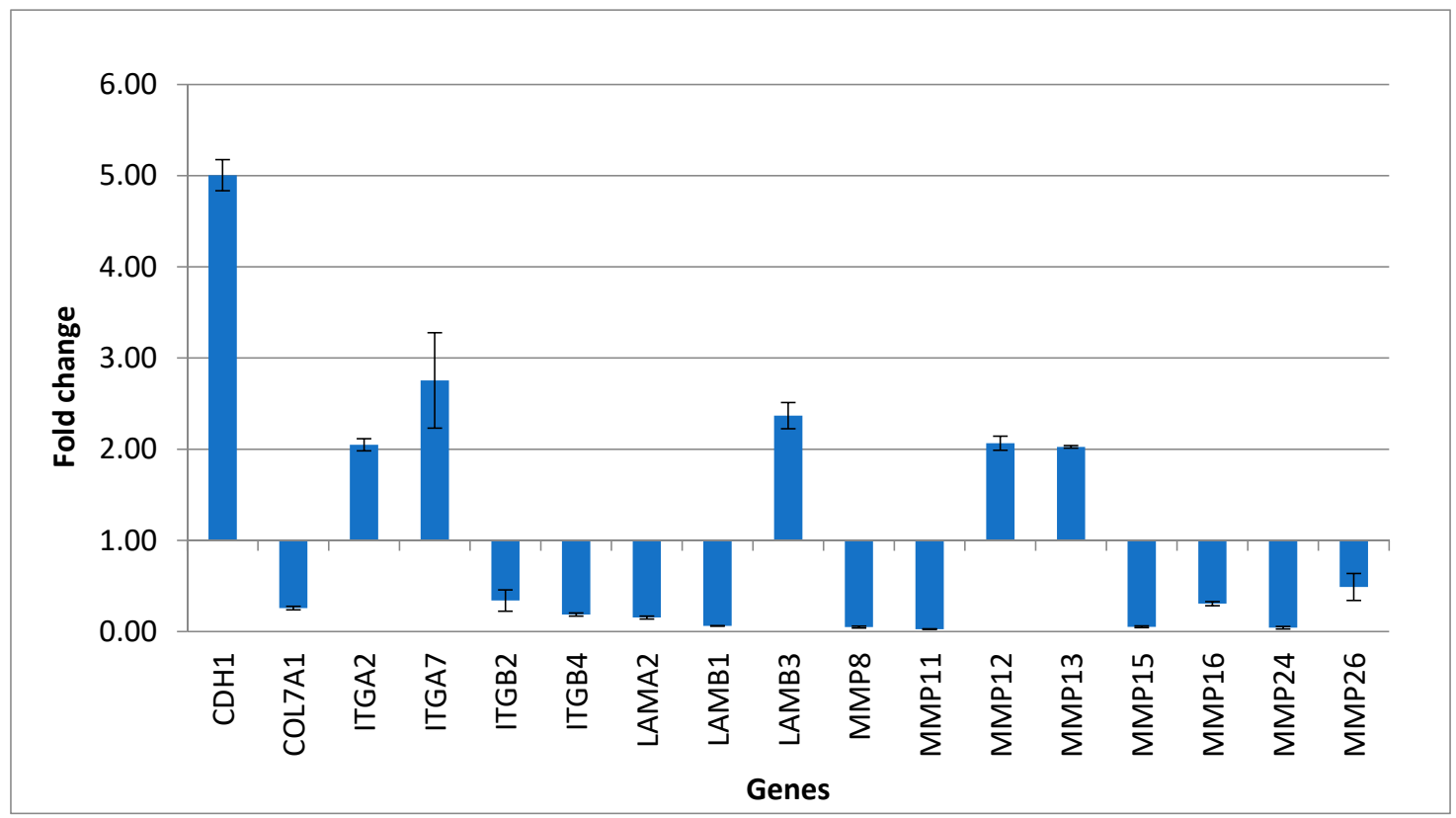

Figure 1. Significant expression levels of the genes up- and downregulated in fibroblast cells treated with mycophenolate (A) and cyclosporine (B) [34].

\section{Discussion}

Our study aimed at establishing how the immunosuppressive therapy with cyclosporine A and mycophenolate mophetil could affect the viability of human gingival fibroblasts and how they may interfere with fibroblasts gene expression, contributing to the development of gingival hyperplasia. The fibroblasts represent the main cellular category in the connective tissue and they carry out very important functions, along with collagen precursor (tropocollagen) and extra-cellular matrix (ECM) precursor secretion and the connective tissue structural integrity preservation. Fibroblasts also have the capacity to regulate the interstitial fluid volume and pressure and they play a role in 
wound healing. These cells also produce matrix metalloproteinases (MMP) and their inhibitors (tissue inhibitors metalloproteinases, TIMP), whose role is to regulate the extracellular degradation of ECM [36]. Along with the role of supporting the connective tissue structure, fibroblasts can produce and respond to cytokines (IL-6, IL-8), chemokines, and growth factors (TGF- $\beta 1$ ) [37]. As the literature reports, gingival hyperplasia induced by immunosuppressive drugs may be the result of the interference with fibroblast proliferation and collagen, ECM molecules, cytokines and growth factors regulation, synthesis, and processing [38]. In this research, fibroblasts treated with both $\mathrm{Mf}$ and CsA solutions at the concentration of $1000 \mathrm{ng} / \mathrm{mL}$ for $24 \mathrm{~h}$, showed a downregulation of extracellular matrix metalloproteases (MMP8, MMP11, MMP15, MMP16, MMP24). Since the family of MMP, including more than twenty enzymes, is responsible for the catabolic turnover of extracellular matrix of the connective tissue, the alteration of the activation of these enzymes may lead to connective tissues accumulation [39,40]. Among the inhibited extracellular matrix metalloproteases there was MMP8. MMP8, also known as neutrophil collagenase, can be produced by fibroblasts, epithelial and endothelial cells, macrophages and neutrophils; its main function is the degradation of type I, II, and III collagens and it emerged to be an anti-tumorigenic and anti-metastatic molecule $[41,42]$. Another downregulated MMP was demonstrated to be MMP11; during normal and pathological conditions it is mostly expressed by fibroblasts later than the other MMPs, indicating that it is involved in downstream tissue remodelling processes; this MMP is secreted under an active form (contrary to the other enzymes of the same family), it has anti-apoptotic function but it does not have the capacity of degrading any major ECM component [43]. On the contrary, our study demonstrated that cell adhesion genes (CDH1) received an upregulation during the fibroblasts treatment with both immunosuppressive drugs. The CDH1 gene encodes for the E-cadherin (or epithelial cadherin), which is a protein that contributes to sticking epithelial cells to each other. Another function of E-cadherin is that of transmitting chemical signals within cells and it acts as a tumor suppressor protein [44]. Data obtained by the enzyme linked immunoassay (ELISA) performed in our study demonstrated higher levels of CDH1 in fibroblasts treated with CsA and Mf than in untreated cells. Contrary to what emerged in our research, the results recorded by $\mathrm{Tu}$ et al. [45] highlighted that CsA could cause a decrease in the production of E-cadherin; other authors supported the same theory: The CsA treatment downregulates the expression of E-cadherin in gingival tissue, an event that compromises basal membrane structure and increases the interaction between epithelial and connective tissue, triggering the fibrotic process $[46,47]$. The 24-h treatment is probably too short to induce a significant change in the expression of the CDH1 gene. Longer time-points should be tested in order to verify the behaviour of this adhesion molecule following treatments with cyclosporin and mycophenolate. The literature reported that the administration of CsA induces the phenomenon of epithelial-mesenchymal transition (EMT) in gingival tissue: EMT is a process in which epithelial cell-cell contacts are weakened, acquiring typical mesenchymal cells characteristics [48]. The reduction of E-cadherin production represents a common sign of EMT. ECM degradation can be performed by metalloproteinase and also through fibroblast phagocytosis, which is regulated by integrins $[49,50]$. Abnormalities in the expression of the ITGA2 gene, encoding for $\alpha 2$-integrin may lead to altered adherence of fibroblasts to collagen, inhibiting phagocytosis [51]. An upregulation of the ITGA2 gene of treated fibroblasts was observed in our study. Zhou et al. confirmed the higher expression of this gene in human gingival fibroblasts treated with CsA, but, on the contrary, Liu et al. [52] found that CsA-treated fibroblasts had a downregulation of ITGA2, compared to the controls.

The results obtained in vitro are indicative of a possible mechanism of action of immunosuppressive drugs on cells. However, these models need further study concerning both the treatment timing and the choice of models that can mimic conditions in vivo as much as possible.

\section{Conclusions}

A chronic administration of cyclosporin A and mycophenolate mophetil was proved to lead to gingival overgrowth. Connective tissue accumulation (caused by inhibition of metalloproteases), 
upregulation of CDH1 (encoding for E-cadherin), ITGA2, ITGA7, LAMB3, MMP12, and MMP13 genes were demonstrated to characterize gingival enlargement induced by immunosuppressive therapy. However, contrasting results reported in the literature require the need for further investigation, in order to clarify the mechanisms involved in this pathologic process.

Author Contributions: Conceptualization, F.C. and D.L.; methodology, A.P.; software, A.P.; validation, G.M., L.L.; formal analysis, A.P.; investigation, D.L.; resources, F.C.; data curation, G.M.; writing-original draft preparation, D.L.; writing—review and editing, A.P.; visualization, L.L.; supervision, F.C.; project administration, D.L.; funding acquisition, F.C. All authors have read and agreed to the published version of the manuscript.

Funding: This research received no external funding.

Conflicts of Interest: The authors declare no conflict of interest.

\section{References}

1. Gawron, K.; Łazarz-Bartyzel, K.; Potempa, J.; Chomyszyn-Gajewska, M. Gingival fibromatosis: Clinical, molecular and therapeutic issues. Orphanet J. Rare Dis. 2016, 11, 9. [CrossRef] [PubMed]

2. Nanda, T.; Singh, B.; Sharma, P.; Arora, K.S. Cyclosporine A and amlodipine induced gingival overgrowth in a kidney transplant recipient: Case presentation with literature review. BMJ Case Rep. 2019, 12, e229587. [CrossRef]

3. Crăiţoiu, Ş.; Bobic, A.G.; Manolea, H.O.; Mehedinţi, M.C.; Pascu, R.M.; Florescu, A.M.; Petcu, I.C.; Osman, A.; Fărcaş-Berechet, C.M.; Iacov-Crăiţoiu, M.M. Immunohistochemical study of experimentally drug-induced gingival overgrowth. Rom. J. Morphol. Embryol. 2019, 60, 95-102.

4. Tungare, S.; Paranjpe, A.G. Drug Induced Gingival Overgrowth (DIGO); StatPearls Publishing: Treasure Island, FL, USA, 2019.

5. Lauritano, D.; Martinelli, M.; Baj, A.; Beltramini, G.; Candotto, V.; Ruggiero, F.; Palmieri, A. Drug-induced gingival hyperplasia: An in vitro study using amlodipine and human gingival fibroblasts. Int. J. Immunopathol. Pharm. 2019, 33. [CrossRef] [PubMed]

6. Madi, M.; Shetty, S.R.; Babu, S.; Achalli, S. Amlodipine-induced Gingival Hyperplasia-A case report and review. West Indian Med. J. 2016, 64, 279-282. [CrossRef]

7. Jose, J.; Santhosh, Y.L.; Naveen, M.R.; Vijay, K. Case report of amlodipine induced gingival hyperplasia-Late onset at a low use. Asian J. Pharm. Clin. Res. 2011, 4, 65-66.

8. Aimetti, M.; Romano, F.; Debernardi, C. Effectiveness of periodontal therapy on the severity of cyclosporin A-induced gingival overgrowth. J. Clin. Periodontol. 2005, 32, 846-850. [CrossRef]

9. Hatahira, H.; Abe, J.; Hane, Y.; Matsui, T.; Sasaoka, S.; Motooka, Y.; Hasegawa, S.; Fukuda, A.; Naganuma, M.; Ohmori, T.; et al. Drug-induced gingival hyperplasia: A retrospective study using spontaneous reporting system databases. J. Pharm. Health Care Sci. 2017, 3, 1-11. [CrossRef]

10. Dongari-Bagtzoglou, A. Informational paper: Drug-associated gingival enlargement. J. Periodontol. 2004, 75, 1424-1431. [CrossRef]

11. Hallmon, W.W.; Rossmann, J.A. The role of drugs in the pathogenesis of gingival overgrowth. A collective review of current concepts. Periodontology 2000 1999, 21, 176-196. [CrossRef]

12. Moffitt, M.L.; Bencivenni, D.; Cohen, R.E. Drug-induced gingival enlargement: An overview. Compend. Contin. Educ. Dent. 2013, 34, 330-336. [PubMed]

13. Van Gelder, T.; Hesselink, D.A. Mycophenolate revisited. Transpl. Int. 2015, 28, 508-515. [CrossRef] [PubMed]

14. Maripuri, S.; Kasiske, B.L. The role of mycophenolate mofetil in kidney transplantation revisited. Transpl. Rev. 2014, 28, 26-31. [CrossRef] [PubMed]

15. Suthanthiran, M.; Morris, R.E.; Strom, T.B. Immunosuppressants: Cellular and molecular mechanisms of action. Am. J. Kidney Dis. 1996, 28, 159-172. [CrossRef]

16. Kataoka, M.; Kido, J.-I.; Shinohara, Y.; Nagata, T. Drug-induced gingival overgrowth-A Review. Boil. Pharm. Bull. 2005, 28, 1817-1821. [CrossRef]

17. Trandafir, D.; Trandafir, V.; Gogalniceanu, D. Gingival overgrowth induced by immunossupressive treatment with cyclosporine a and Mycofenolate mofetil in a patient with kidney transplant-A case report and a literature preview. Int. J. Med. Dent. 2013, 3, 183-187. 
18. Ghafari, A.; Poorabbas, R.; Anvieh Takieh, J.; Sepehrvand, N.; Kargar, C.; Hatami, S. Gingival enlargement and its risk factors in kidney transplant patients rceiving Cyclosporine A. Iran. J. Kidney Dis. 2010, 4, 66-70.

19. de la Rosa García, E.; Mondragón Padilla, A. The effect of mycophenolate mophetil and azathioprine on gingival overgrowth associated with cyclosporin a use in kidney transplant patients. Nefrología 2009, 29, 474-478.

20. Ramírez-Rámiz, A.; Brunet-Llobet, L.; Lahor-Soler, E.; Miranda, J. On the cellular and molecular mechanisms of drug-induced gingival overgrowth. Open Dent. J. 2017, 11, 420-435. [CrossRef]

21. Malek, R.; El Houari, B.; Kissa, J. Periodontal management of Cyclosporin A-Induced gingival overgrowth: A nonsurgical approach. Case Rep. Dent. 2019, 2019. [CrossRef]

22. Trackman, P.C.; Kantarci, A. Molecular and clinical aspects of drug-induced gingival overgrowth. J. Dent. Res. 2015, 94, 540-546. [CrossRef] [PubMed]

23. Rapone, B.; Ferrara, E.; Santacroce, L.; Cesarano, F.; Arazzi, M.; Di Liberato, L.; Scacco, S.; Grassi, R.; Grassi, F.R.; Gnoni, A.; et al. Periodontal microbiological status influences the occurrence of Cyclosporine-A and Tacrolimus-induced gingival overgrowth. Antibiotics 2019, 8, 124. [CrossRef] [PubMed]

24. Villalobos, I.M.; Redondo-De Oro, K.; Díaz Caballero, A. Case report: Gingival overgrowth induced by sirolimus in a patient with kidney transplant. Sch. J. Dent. Sci. 2015, 2, 181-183.

25. Yoshida, T.; Nagata, J.; Yamane, A. Growth factors and proliferation of cultured rat gingival cells in response to Cyclosporin A. J. Periodontal Res. 2005, 40, 11-19. [CrossRef] [PubMed]

26. Vahabi, S.; Salman, B.N.; Rezazadeh, F.; Namdari, M. Effects of cyclosporine and phenytoin on biomarker expressions in gingival fibroblasts of children and adults: An in vitro study. J. Basic Clin. Physiol. Pharm. 2014, 25, 167-173. [CrossRef] [PubMed]

27. Ponnaiyan, D.; Jegadeesan, V. Cyclosporine A: Novel concepts in its role in drug-induced gingival overgrowth. Dent. Res. J. 2016, 12, 499-506. [CrossRef]

28. Chae, H.-J.; Ha, M.-S.; Yun, D.-H.; Pae, H.-O.; Chung, H.-T.; Chae, S.-W.; Jung, Y.-K.; Kim, H.-R. Mechanism of Cyclosporine-induced overgrowth in gingiva. J. Dent. Res. 2006, 85, 515-519. [CrossRef]

29. Ganesh, P.R. Immunoexpression of interleukin-6 in drug-induced gingival overgrowth patients. Contemp. Clin. Dent. 2016, 7, 140-145. [CrossRef]

30. Cotrim, P.; Martelli-Júnior, H.; Graner, E.; Sauk, J.; Coletta, R. Cyclosporin A Induces proliferation in human gingival fibroblasts via induction of transforming growth factor- $\beta 1$. J. Periodontol. 2003, 74, 1625-1633. [CrossRef]

31. Yamaguchi, M.; Naruishi, K.; Yamada-Naruishi, H.; Omori, K.; Nishimura, F.; Takashiba, S. Long-term cyclosporin A exposure suppresses cathepsin-B and -L activity in gingival fibroblasts. J. Periodontal Res. 2004, 39, 320-326. [CrossRef]

32. Gong, Y.; Lu, J.; Ding, X.; Yu, Y. Effect of adjunctive roxithromycin therapy on interleukin-1 $\beta$, transforming growth factor- $\beta 1$ and vascular endothelial growth factor in gingival crevicular fluid of cyclosporine A-treated patients with gingival overgrowth. J. Periodontal Res. 2013, 49, 448-457. [CrossRef]

33. Wu, K.-J.; Huang, G.-F.; Chen, C.-H.; Chang, H.-H.; Deng, Y. Cyclosporine A induces connective tissue growth factor expression in human gingival fibroblasts: Suppression by epigallocatechin-3-gallate. J. Med. Assoc. 2014, 113, 828-832. [CrossRef] [PubMed]

34. Lauritano, D.; Palmieri, A.; Lucchese, A.; Di Stasio, D.; Moreo, G.; Carinci, F. Role of Cyclosporine in gingival hyperplasia: An in vitro study on gingival fibroblasts. Int. J. Mol. Sci. 2020, 21, 595. [CrossRef] [PubMed]

35. Schmittgen, T.D.; Livak, K.J. Analyzing real-time PCR data by the comparative CT method. Nat. Protoc. 2008, 3, 1101-1108. [CrossRef] [PubMed]

36. McAnulty, R. Fibroblasts and myofibroblasts: Their source, function and role in disease. Int. J. Biochem. Cell Boil. 2007, 39, 666-671. [CrossRef] [PubMed]

37. Van Linthout, S.; Miteva, K.; Tschöpe, C. Crosstalk between fibroblasts and inflammatory cells. Cardiovasc. Res. 2014, 102, 258-269. [CrossRef]

38. Gürkan, A.; Becerik, S.; Öztürk, V.Ö; Atmaca, H.; Atilla, G.; Emingil, G. Interleukin-6 family of Cytokines in crevicular fluid of renal transplant recipients with and without Cyclosporine A-Induced gingival overgrowth. J. Periodontol. 2015, 86, 1069-1077. [CrossRef]

39. Brown, R.S.; Arany, P.R. Mechanism of drug-induced gingival overgrowth revisited: A unifying hypothesis. Oral Dis. 2014, 21, e51-e61. [CrossRef] 
40. Wang, X.; Khalil, R.A. Matrix metalloproteinases, vascular remodeling, and vascular disease. Adv. Pharmacol. 2018, 81, 241-330. [CrossRef]

41. Van Lint, P.; Libert, C. Matrix metalloproteinase-8: Cleavage can be decisive. Cytokine Growth Factor Rev. 2006, 17, 217-223. [CrossRef]

42. Decock, J.; Hendrickx, W.; Thirkettle, S.; Gutiérrez-Fernández, A.; Robinson, S.D.; Edwards, D.R. Pleiotropic functions of the tumor- and metastasis-suppressing matrix metalloproteinase- 8 in mammary cancer in MMTV-PyMT transgenic mice. Breast Cancer Res. 2015, 17, 38. [CrossRef]

43. Matziari, M.; Dive, V.; Yiotakis, A. Matrix metalloproteinase 11 (MMP-11; stromelysin-3) and synthetic inhibitors. Med. Res. Rev. 2007, 27, 528-552. [CrossRef] [PubMed]

44. Pecina-Slaus, N. Tumor suppressor gene E-cadherin and its role in normal and malignant cells. Cancer Cell Int. 2003, 3, 17. [CrossRef]

45. Tu, H.-P.; Chen, Y.-T.; Shieh, Y.-S.; Chin, Y.-T.; Huang, R.-Y.; Yang, S.-F.; Gau, C.-H.; Fu, E. Cyclosporin-induced downregulation of the expression of E-Cadherin during proliferation of edentulous Gingival Epithelium in rats. J. Periodontol. 2006, 77, 832-839. [CrossRef]

46. Sume, S.S.; Kantarci, A.; Lee, A.; Hasturk, H.; Trackman, P.C. Epithelial to mesenchymal transition in gingival overgrowth. Am. J. Pathol. 2010, 177, 208-218. [CrossRef] [PubMed]

47. Yang, F.; Lu, J.; Yu, Y.; Gong, Y. Epithelial to mesenchymal transition in Cyclosporine A-Induced rat gingival overgrowth. Arch. Oral Boil. 2017, 81, 48-55. [CrossRef]

48. Lamouille, S.; Subramanyam, D.; Blelloch, R.; Derynck, R. Regulation of epithelial-mesenchymal and mesenchymal-epithelial transitions by microRNAs. Curr. Opin. Cell Boil. 2013, 25, 200-207. [CrossRef] [PubMed]

49. van der Pauw, M.T.; Bos, T.V.D.; Everts, V.; Beertsen, W. Phagocytosis of fibronectin and collagens type i, iii, and $\mathrm{v}$ by human gingival and periodontal ligament fibroblasts in vitro. J. Periodontol. 2001, 72, 1340-1347. [CrossRef] [PubMed]

50. Ríos, M.H.; Sorsa, T.; Obregón, F.; Tervahartiala, T.; Valenzuela, M.A.; Pozo, P.; Dutzan, N.; Lesaffre, E.; Molas, M.; Gamonal, J. Proteolytic roles of matrix metalloproteinase (MMP)-13 during progression of chronic periodontitis: Initial evidence for MMP-13/MMP-9 activation cascade. J. Clin. Periodontol. 2009, 36, 1011-1017. [CrossRef]

51. Gürkan, A.; Emingil, G.; Afacan, B.; Berdeli, A.; Atilla, G. Alpha 2 integrin gene (ITGA2) polymorphism in renal transplant recipients with and without drug induced gingival overgrowth. Arch. Oral Boil. 2014, 59, 283-288. [CrossRef]

52. Liu, C.; Tao, T.; Zhao, L.; Ding, Y. Decreased Alpha 2 integrin gene expression in non-familial gingival fibromatosis: A report of two cases. Int. J. Clin. Exp. Pathol. 2017, 10, 7492-7497. [PubMed] 